\title{
Effect of heat conductivity and thickness of substrate on thermocapillary rupture of locally heated horizontal liquid film
}

\author{
Dmitry Kochkin ${ }^{1,2, *}$, Veronica Sulyaeva ${ }^{3}$ \\ ${ }^{1}$ Kutateladze Institute of Thermophysics SB RAS, 630090 Novosibirsk, Russia \\ ${ }^{2}$ Novosibirsk State Technical University, 630073 Novosibirsk, Russia \\ ${ }^{3}$ Nikolaev Institute of Inorganic Chemistry SB RAS, 630090 Novosibirsk, Russia
}

\begin{abstract}
Experimental results on thermocapillary rupture of a horizontal locally heated water film on the removable substrates of different thicknesses, made of materials with different heat conductivity, are presented in this paper. The studies have shown that with an increase in substrate heat conductivity and thickness, the critical heat flux, required for rupture of the film, increases. The heat flux redistributes over the copper and brass substrates; at that, the local character of heat flux is lost, and rupture does not occur.
\end{abstract}

\section{Introduction}

The devices, which use liquid film flow, are widely used in industry. Thin liquid films are promising for cooling the equipment with high local heat generation, in particular, highperformance electronics [1-3]. Film cooling systems are effective because they provide high intensity of heat and mass transfer at relatively low coolant flow rates. Reducing the film thickness allows intensification of heat and mass transfer, but thin films are inclined to rupture, which causes a rapid increase in temperature of the cooled section and its breakdown.

The thermocapillary rupture of the locally heated liquid film flowing down under the action of gravity for the first time was studied in [4-6]. The influence of substrate wettability and liquid properties on thermocapillary rupture of the falling films was investigated in [7-9]. The effect of substrate structuring on the break of the falling liquid films was studied in [10]. The thermocapillary rupture of a horizontal liquid layer for the first time was investigated in $[11,12]$. Studies of $[7,13]$ have shown that the critical heat flux for the horizontal liquid films can be several times higher than the heat flux for the films falling under the action of gravity. This explains the relevance of our research.

The main aim of our study is to determine the dependence of the critical heat flux on the thickness of horizontal liquid film on the substrates of different materials and different thicknesses.

\footnotetext{
* Corresponding author: kochkin1995@mail.ru
} 


\section{Experimental setup}

The experiments were carried out on locally heated substrates of copper, brass, stainless steel, and glass with the diameter of $50.8 \mathrm{~mm}$ and thickness of 1 and $3 \mathrm{~mm}$. The substrate was placed on the textolite base with the copper rod of $12.7 \mathrm{~mm}$ in diameter (Fig. 1). A ceramic heater was connected to the rod from the bottom. The heat flux was determined by electrical power released on the ceramic heater. Distilled water with the initial temperature of $25^{\circ} \mathrm{C}$ was used as the working liquid. The liquid was fed to the substrate using a syringe pump. The substrate was cooled along the edges with the help of a cooling circuit (Fig. 1). The water temperature in the cooling circuit was either 10 or $25^{\circ} \mathrm{C}$.

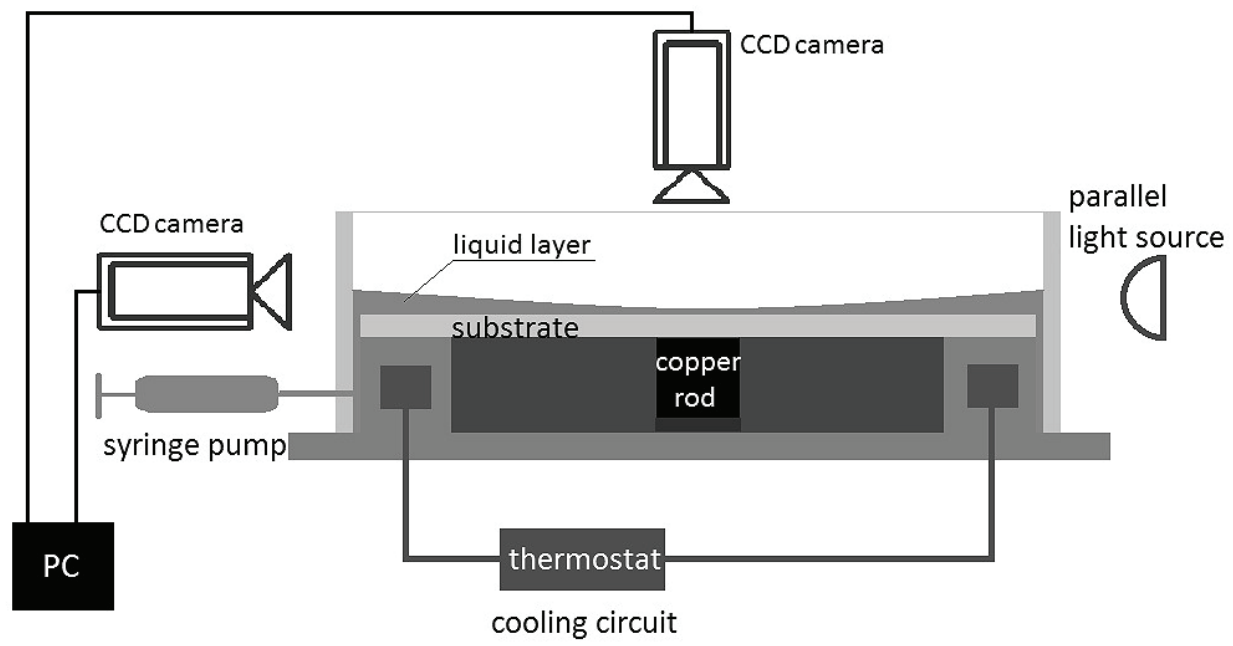

Fig. 1. Layout of setup (power source of the heater is not shown).

To determine the film thickness, we applied the optical method using the CCD DMK 23GP031 digital camera and source of parallel light MI-150 (Fig. 1). Another camera was placed above the test section to observe film rupture dynamics.

The morphology of the surface of the glass substrate was analyzed using a scanning electron microscope (HITACHI S3400N) and atomic force microscope (Solver Pro NT MDT), Fig. 2. The root mean square (RMS) surface roughness was found to be $5.417 \mathrm{~nm}$, with the average roughness of $4.057 \mathrm{~nm}$.

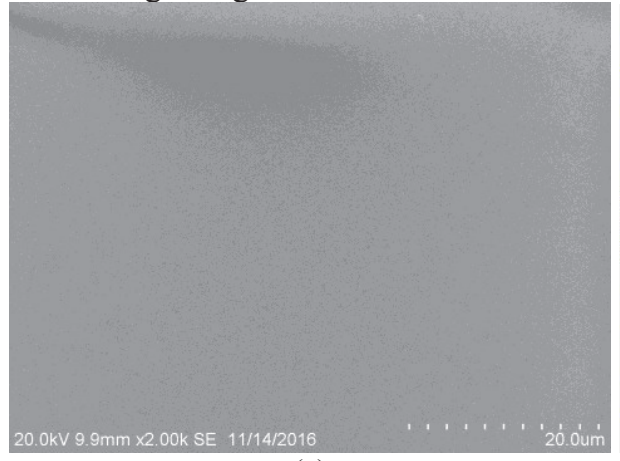

(a)

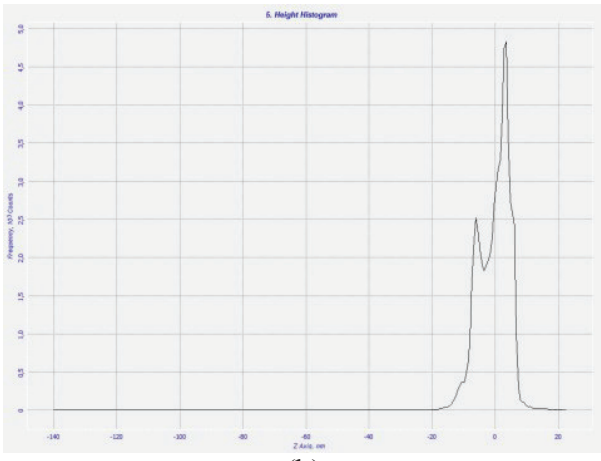

(b)

Fig. 2. Image of the glass substrate surface obtained using scanning electron microscope (a), and height histogram obtained using atomic force microscope (b). 


\section{Results of experiment}

Dependence of the critical heat flux on initial liquid film thickness on stainless steel substrates with the thicknesses of 1 and $3 \mathrm{~mm}$, and glass substrate of $3-\mathrm{mm}$ thickness is shown in Fig. 3. It is seen that on the stainless steel substrates of 1-mm thickness, the critical heat flux is several times lower than on the substrates of the same material with the thickness of $3 \mathrm{~mm}$. This suggests that increasing the substrate thickness, we increase its thermal resistance, therefore, the temperature on the substrate surface becomes lower, the local heat flux density also decreases due to increased heat spreading into the substrate, and the critical heat flux increases due to the effect of these two factors. According to comparison of dependencies for the 3-mm substrates of stainless steel and glass, the critical heat flux on the stainless steel substrate is several times higher than on the glass substrate. Apparently, this is caused by the fact that heat conductivity of stainless steel is $\sim 20$ times higher than heat conductivity of glass, and heat flow spreading into the substrate is much larger; at that, heating localization decreases and the critical heat flux becomes higher.

In Fig. 3, our data are compared with results of [7] on rupture of a horizontal water layer on the stainless steel substrate with an in-built copper heater of $1 \mathrm{x} 1 \mathrm{~cm}$, set into a steel plate (without removable substrates). The difference between our data and data of [7] can be, probably, caused by the fact that due to heat spreading, the heat flux density on the working surface in experiment of [7] can be either lower than in our experiment (for the 3-mm glass substrate and 1-mm steel substrate) or higher (for the 3-mm steel substrate).

In the experiments on the copper and brass substrates of 1-mm and 3-mm thickness, the film rupture in the range of heat fluxes of up to $60 \mathrm{~W}$ was not observed. Due to high heat conductivity of these materials, the local character of heating was lost because the heat flux was redistributed over the substrate and discharged into the cooling circuit.

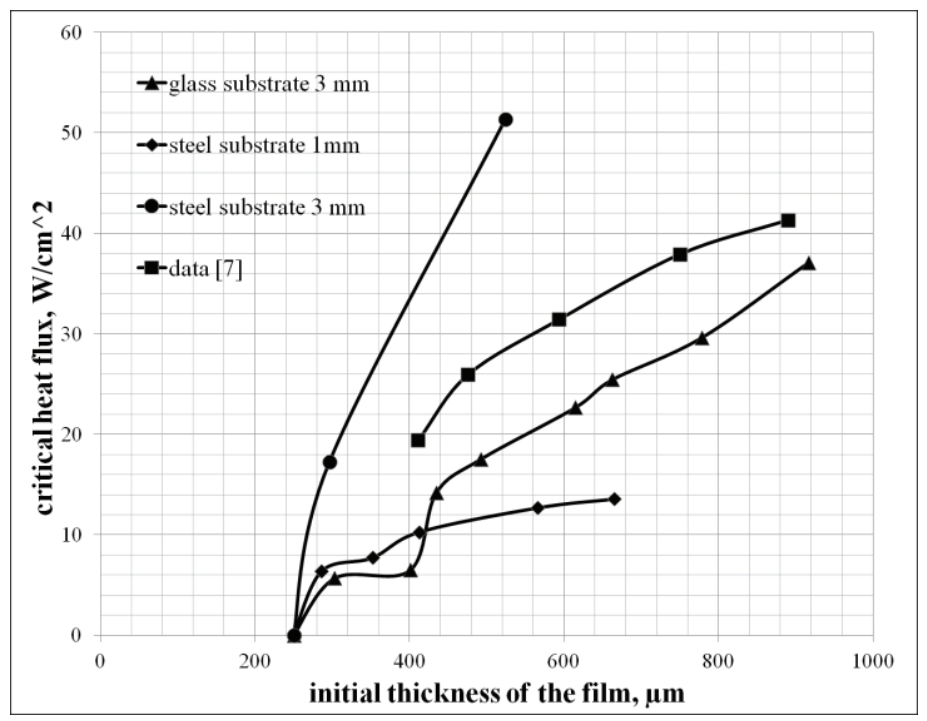

Fig. 3. Dependence of the critical heat flux on initial film thickness. 

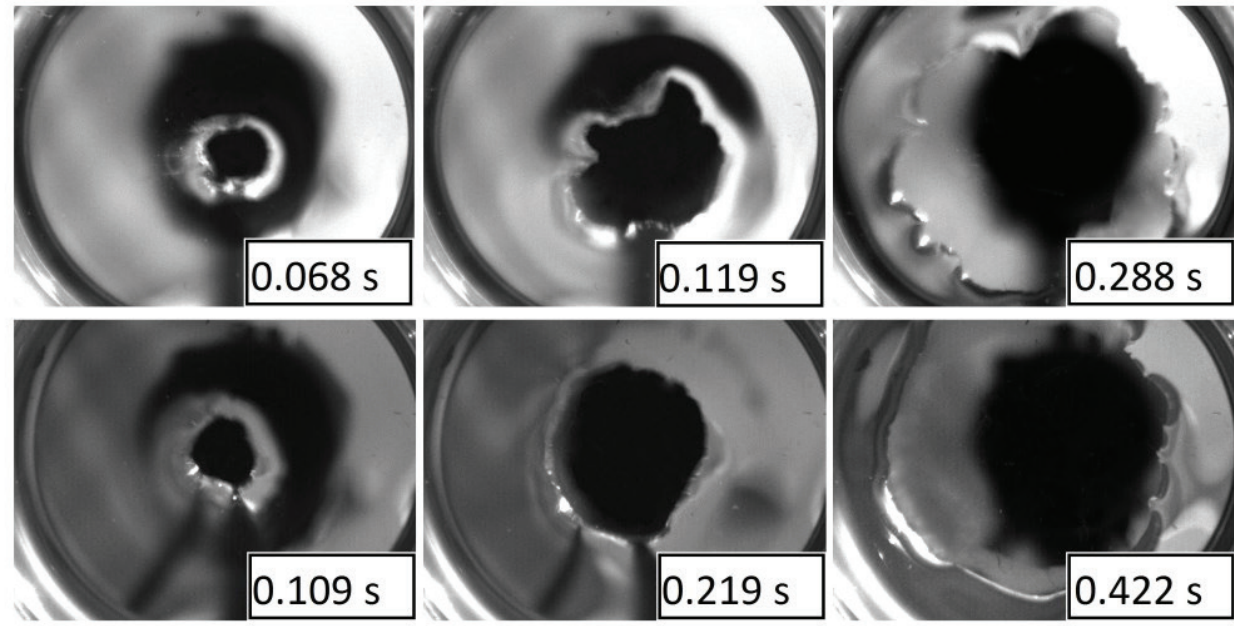

Fig. 4. Dynamics of dry spot spreading. The upper and lower series of pictures - film with the thickness of $0.4 \mathrm{~mm}\left(\mathrm{q}=6.86 \mathrm{~W} / \mathrm{cm}^{2}\right)$ and $0.83 \mathrm{~mm}\left(\mathrm{q}=18.6 \mathrm{~W} / \mathrm{cm}^{2}\right)$, respectively. Time from the moment of film rupture onset is indicated.

Dynamics of dry spot spreading (on the glass substrate of 3-mm thickness) on the film with a thickness of $0.4 \mathrm{~mm}$ at $\mathrm{q}=6.86 \mathrm{~W} / \mathrm{cm}^{2}$ and film with thickness of $0.83 \mathrm{~mm}$ at $\mathrm{q}=$ $18.6 \mathrm{~W} / \mathrm{cm}^{2}$ are shown in Fig. 4. It is seen that a dry spot in both cases is formed in the substrate center above the heater and it spreads throughout the substrate. As can be seen according to times, indicated in Fig. 4, the velocity of dry spot spreading for the film thickness of $0.4 \mathrm{~mm}$ is slightly higher than for the film with thickness of $0.83 \mathrm{~mm}$.

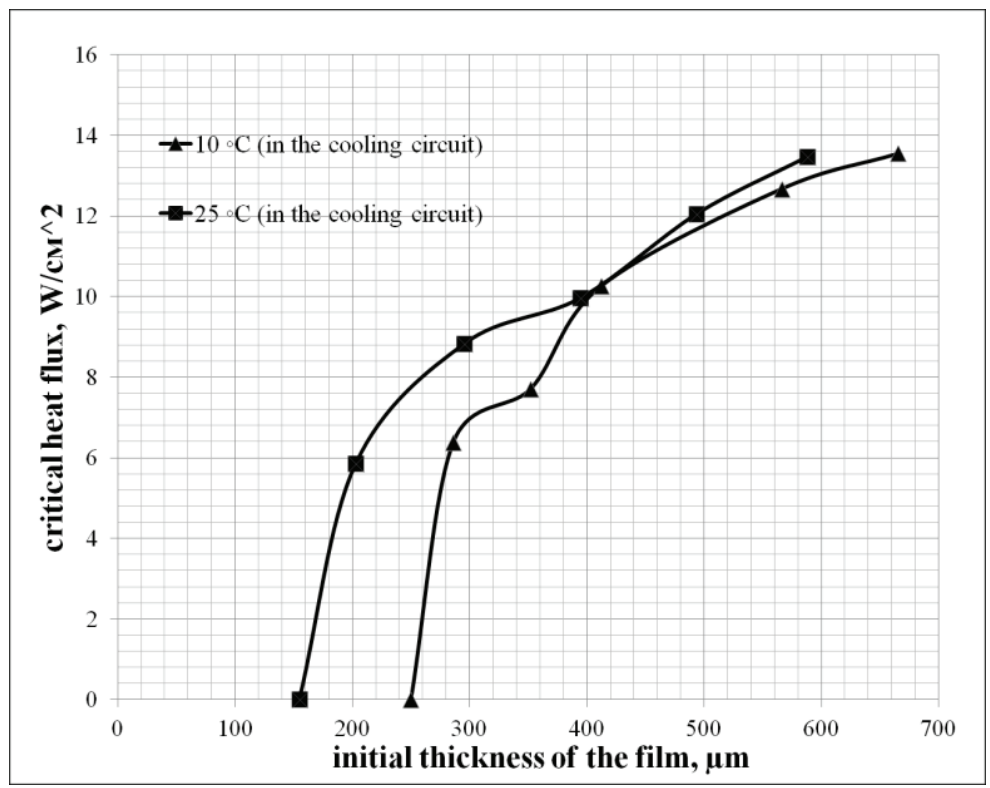

Fig. 5. Dependence of the critical heat flux on initial film thickness at different temperatures in the cooling circuit.

Dependence of the critical heat flux on initial film thickness on the stainless steel substrates of 1-mm thickness is shown in Fig. 5 for different water temperatures in the 
cooling circuit $\left(10^{\circ} \mathrm{C}\right.$ and $\left.25^{\circ} \mathrm{C}\right)$. At water temperature of $10^{\circ} \mathrm{C}$ in the cooling circuit, the film is broken at the thickness of $\sim 250 \mu \mathrm{m}$ without heater switching on. This is due to the influence of thermocapillary forces caused by the difference between the temperature of water in the cooling circuit and air in the room. Increasing the temperature of water in the cooling circuit to the temperature of air in the room $\left(25^{\circ} \mathrm{C}\right)$ eliminates thermocapillary effect with breakdown of films with the thickness higher than $\sim 200 \mu \mathrm{m}$. As seen from Fig. 5 , for liquid films with initial thickness higher than $\sim 400 \mu \mathrm{m}$ the water temperature in the cooling circuit stops to significantly influence on the critical heat flux.

\section{Conclusion}

It was found out that with an increase in heat conductivity and substrate thickness, the critical heat flux required for film rupture increases. When using the substrates made of materials with high heat conductivity (copper, brass), the heat flux is redistributed over the substrate, and heat is removed to the cooling circuit; at that, there is no film rupture.

This work was supported by the Ministry of Education and Science of Russia (Agreement No 14.604.21.0053, project identifier RFMEFI60414X0053).

\section{References}

1. A. Bar-Cohen, P. Wang. ASME. J. Heat Transfer, 134, 051017 (2012)

2. E.Ya. Gatapova, O.A. Kabov, Microgravity Science and Technology, 19-3/4, 132, (2007)

3. D.V. Zaitsev, D.A. Rodionov, O.A. Kabov, Technical Physics L etters, 35, 680 (2009)

4. O.A. Kabov, Thermophysics and Aerodynamics, 7, 513 (2000)

5. E.A. Chinnov, O.A. Kabov, A.V. Muzykantov and D.V. Zaitsev, Intern. Journal of Heat and Technology, 19, 31 (2001)

6. D.V. Zaitsev, D.A. Rodionov, O.A. Kabov, Microgravity science and technology, 193/4, 100 (2007)

7. D. V. Zaitsev, D. P. Kirichenko, and O. A. Kabov, Technical Physics Letters, 41, 551 (2015)

8. D. V. Zaitsev, O. A. Kabov, V. V. Cheverda, and N. S. Bufetov, High Temperature, 42, 450 (2004)

9. D.V. Zaitsev, A.A. Semenov, and O.A. Kabov, Thermophysics and Aeromechanics, 23, 625 (2016)

10. D.V. Zaitsev, A.M. Lozano, H. Auracher, O.A. Kabov, Microgravity science and technology, 19-3/4, 71 (2007)

11. A. Orell, S.G. Bankoff, Int. J. Heat and Mass Transfer, 14, 1835 (1971)

12. J. P. Burelbach, S.G. Bankoff, S.H. Davis, Phys. Fluids A 2, 321 (1990)

13. D.V. Zaitsev, O.A. Kabov, Microgravity science and technology, 19-3/4, 174 (2007) 